\title{
A Total Synthesis of Tarchonanthuslactone Exploiting N-Pyrrole Carbinols as Efficient Stereocontrolling Elements
}

Mark S. Scott, ${ }^{\dagger}$ Chris A. Luckhurst, ${ }^{\ddagger}$ and Darren J. Dixon $^{\S *}$

'University Chemical Laboratories, University of Cambridge, Lensfield Road, Cambridge CB2 1EW, UK,

${ }^{\ddagger}$ AstraZeneca R\&D Charnwood, Bakewell Road, Loughborough, LE11 5RH, UK, and ${ }^{\S}$ School of Chemistry, The University of

Manchester, Oxford Road, Manchester M13 9PL, UK.

Darren.Dixon@man.ac.uk

Supporting Information

NMR Spectra. 


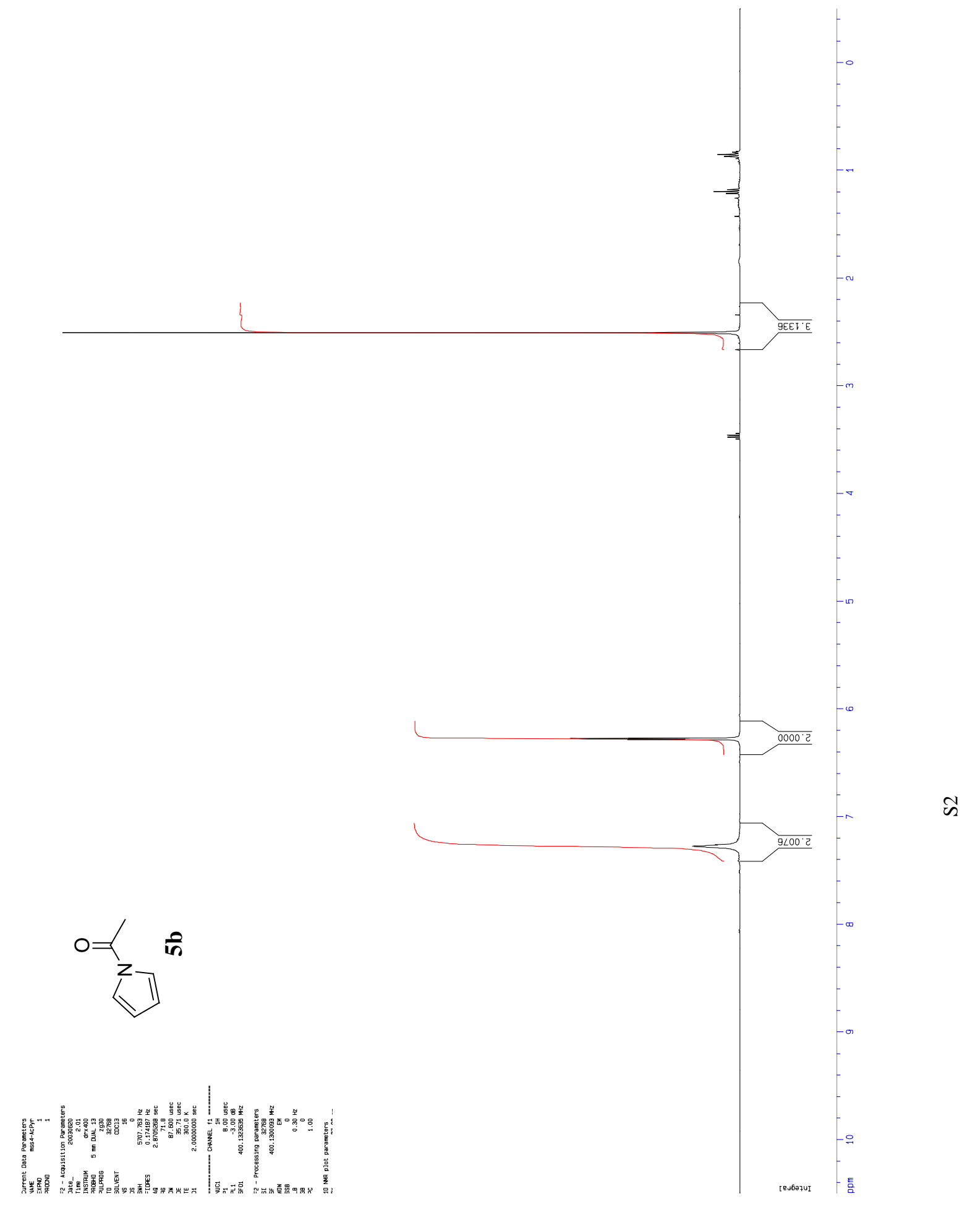




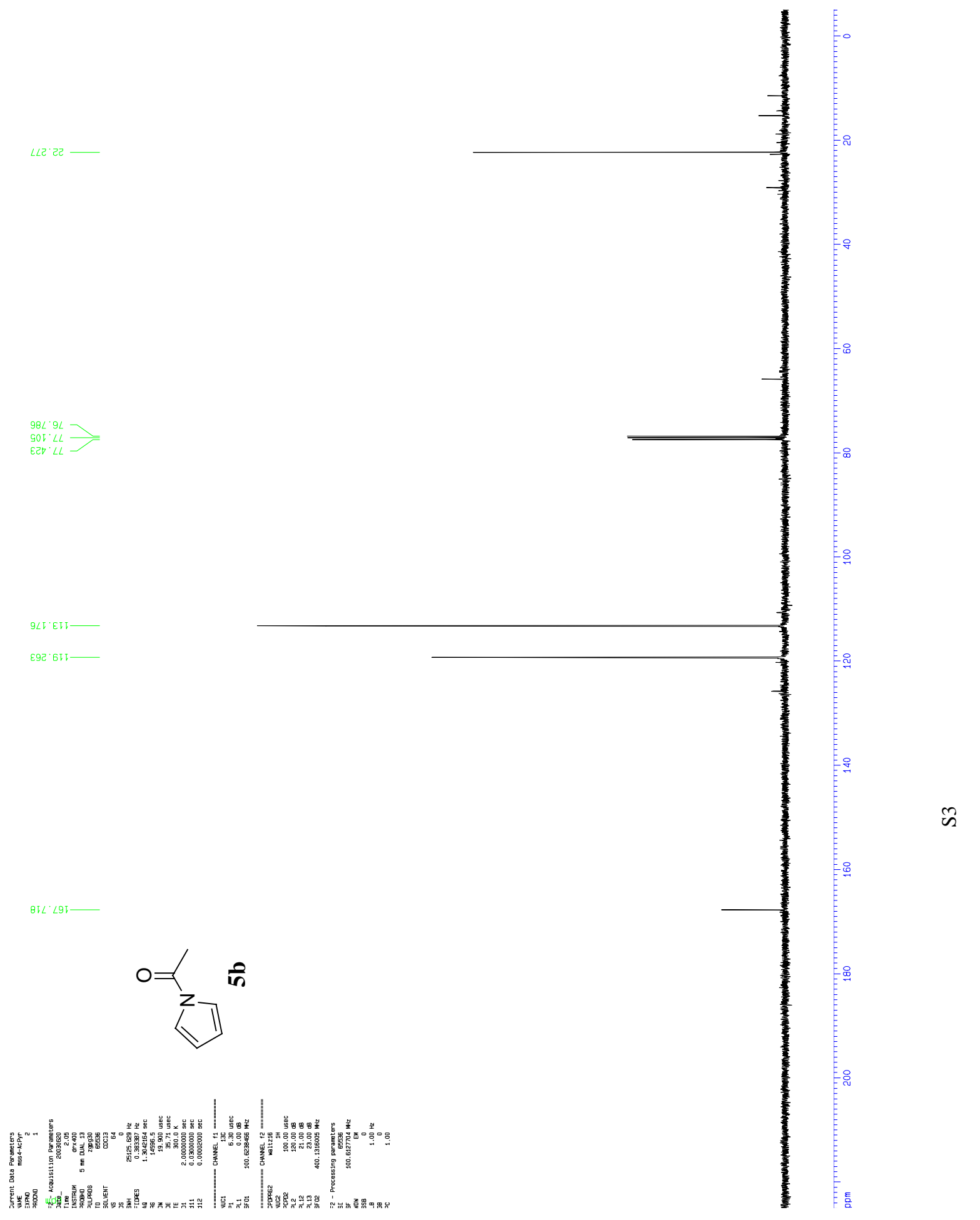




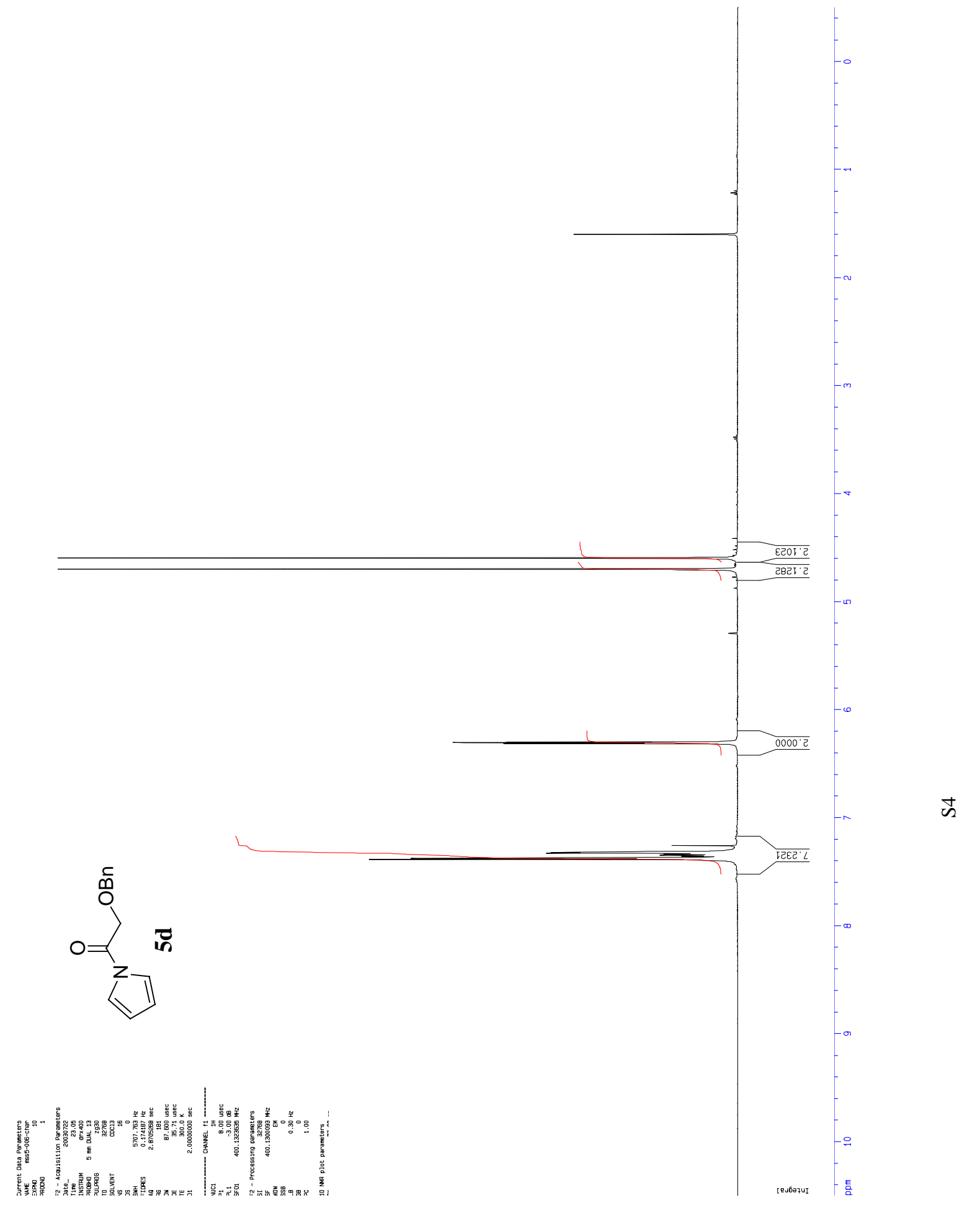




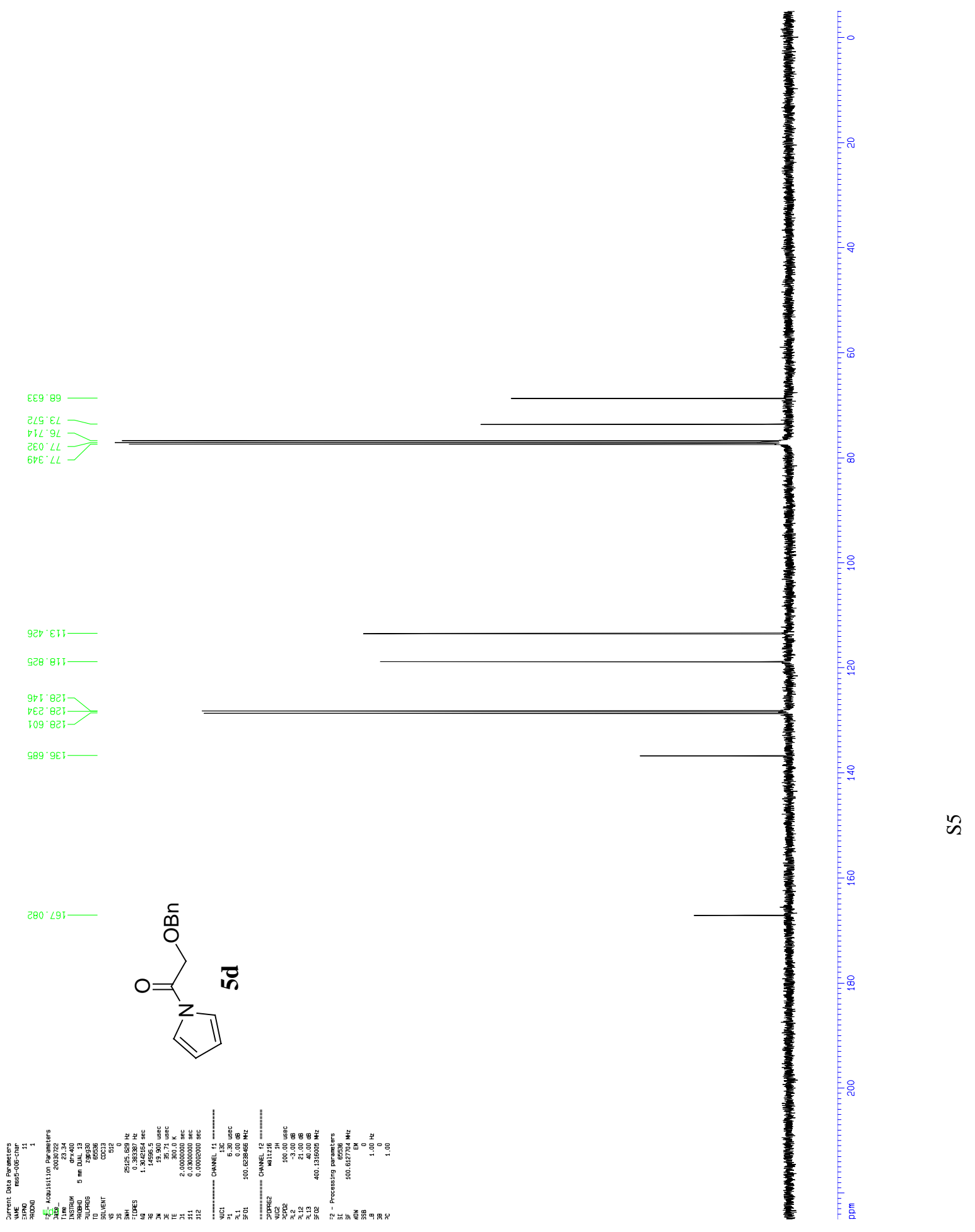




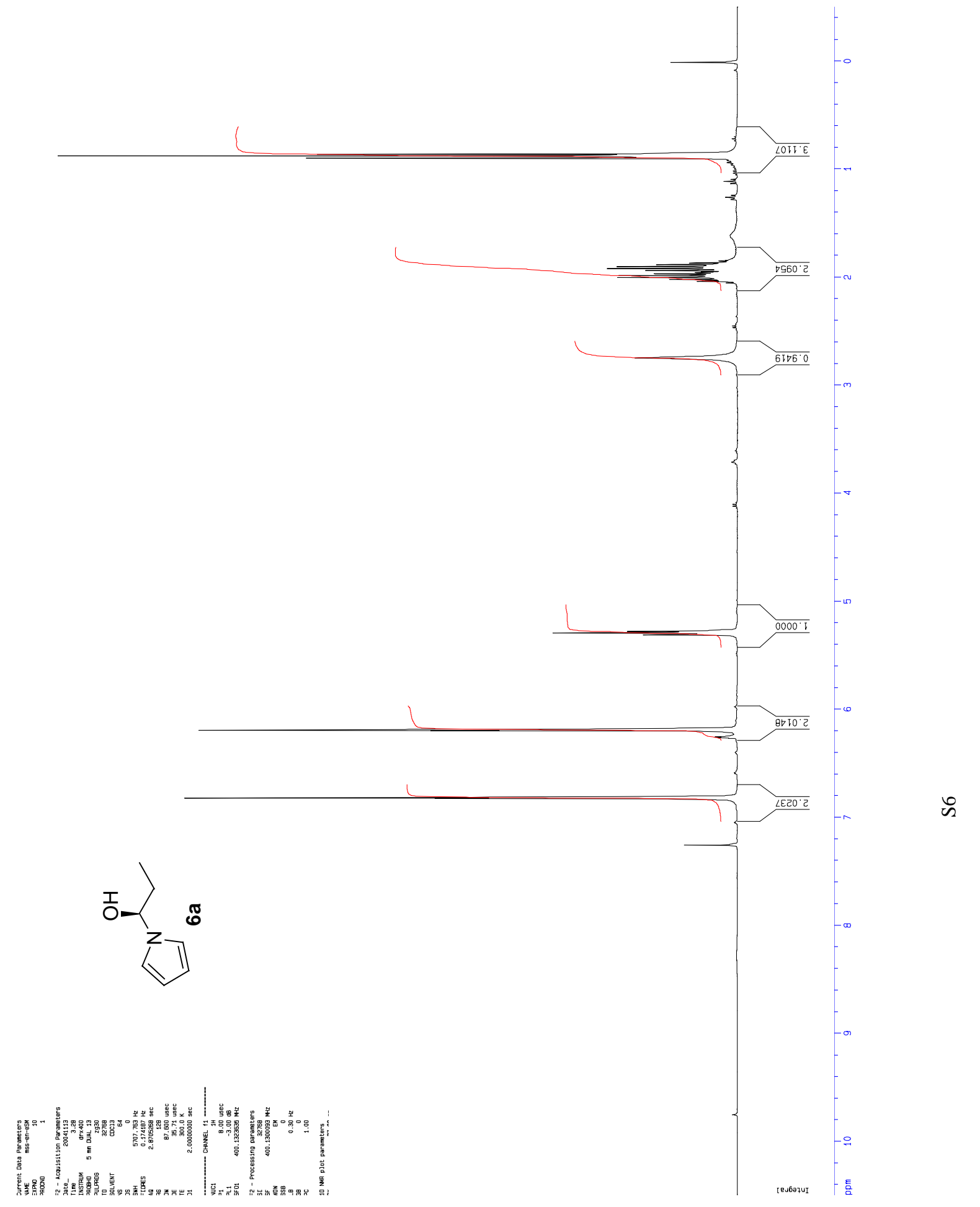



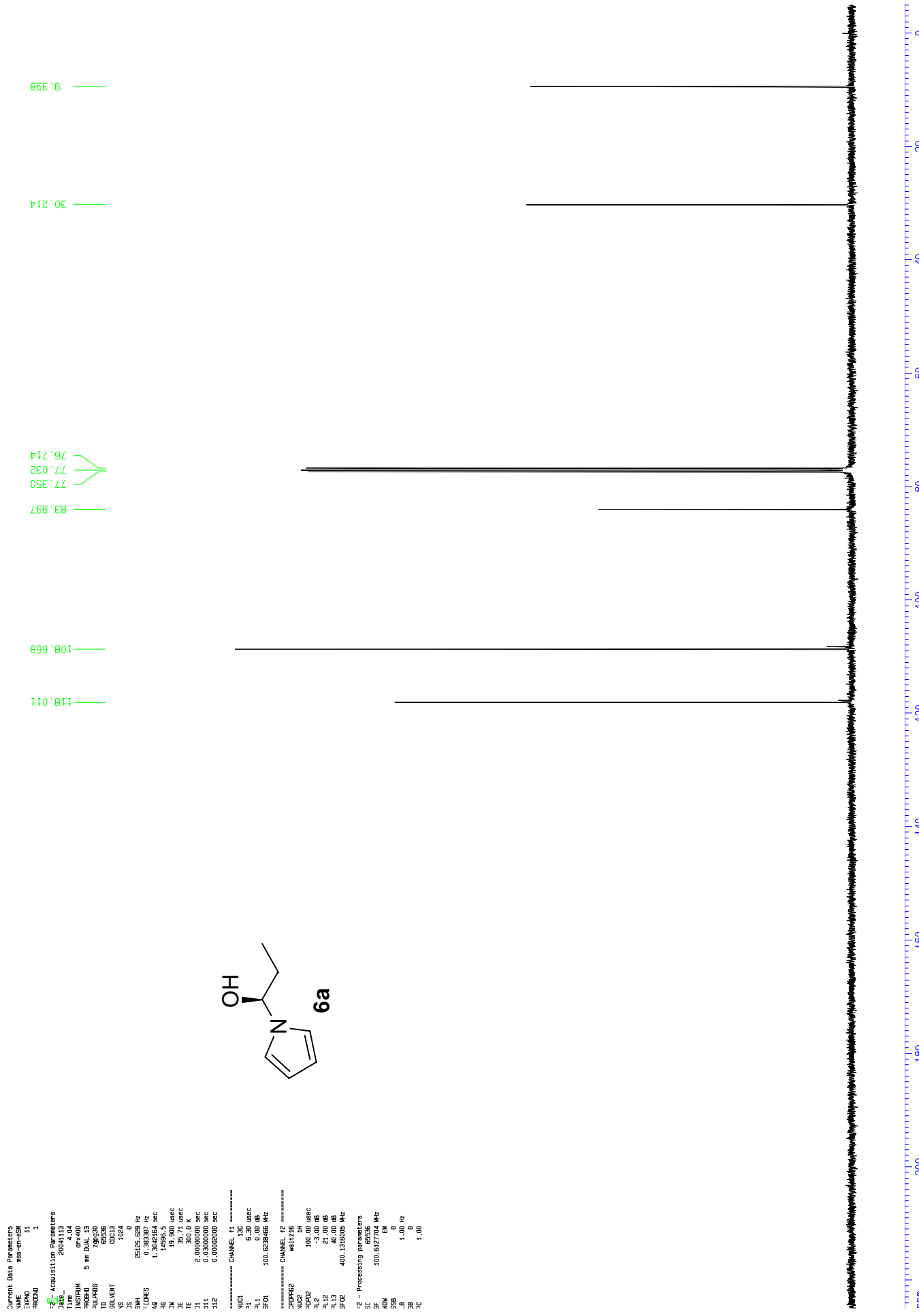


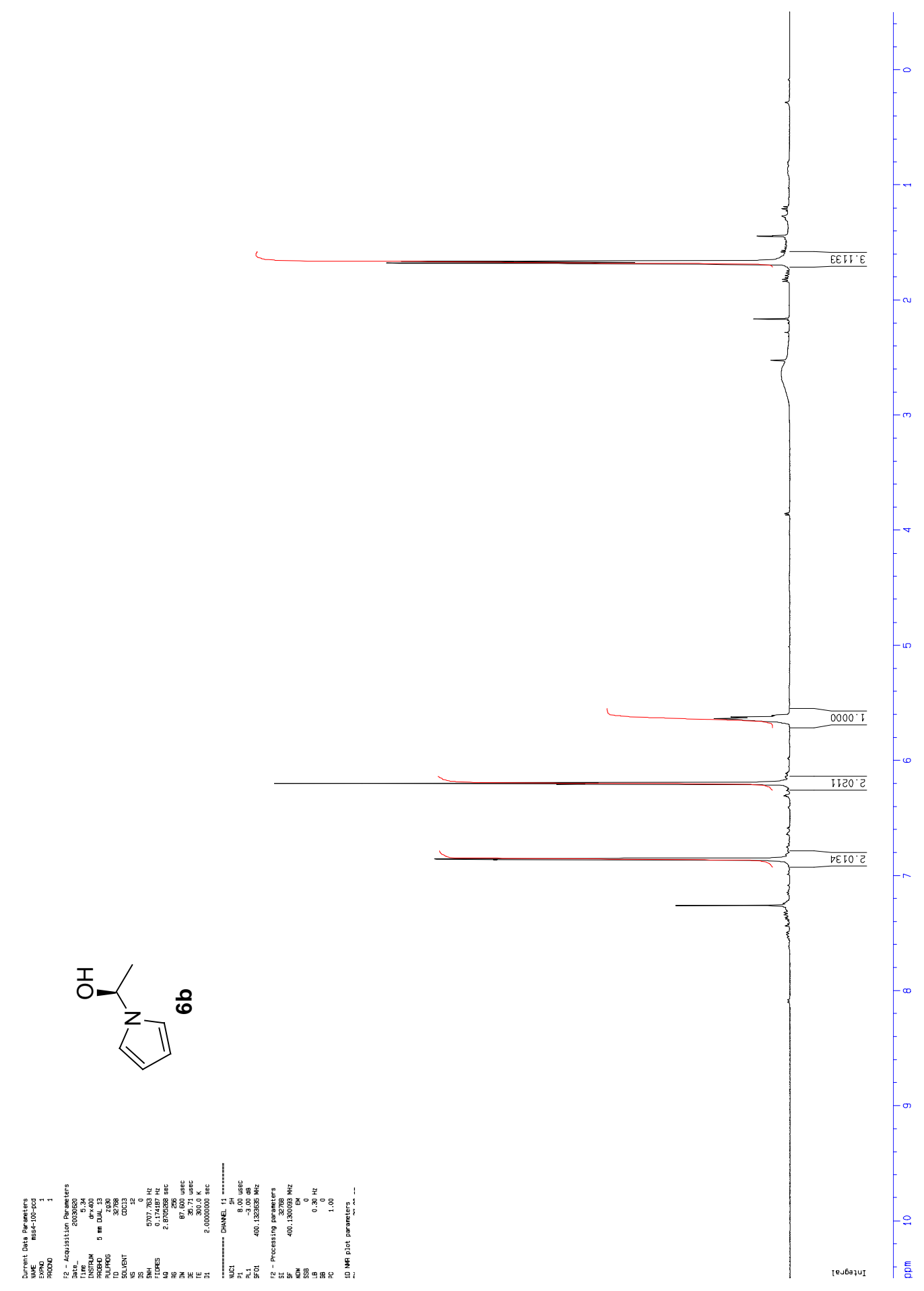




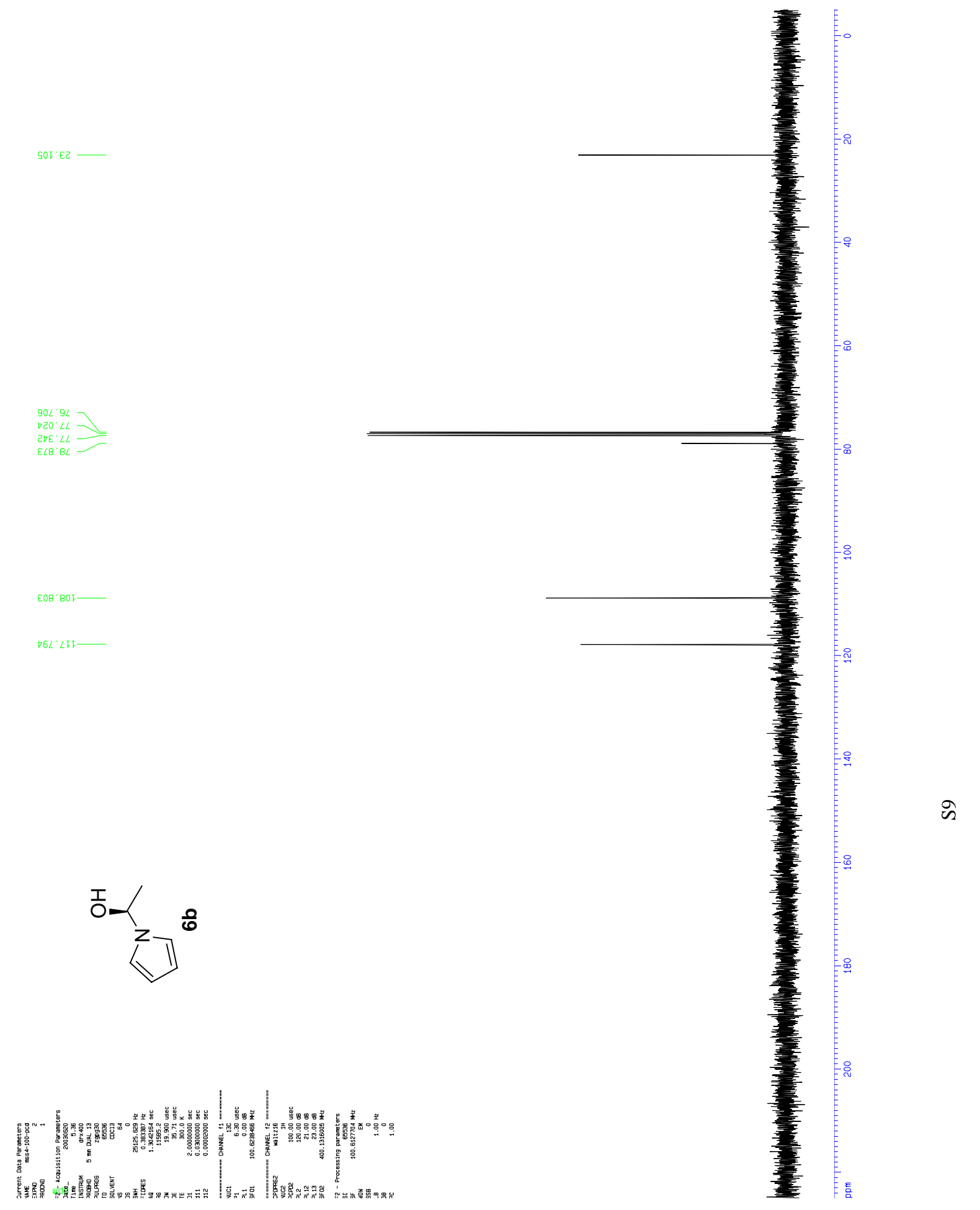




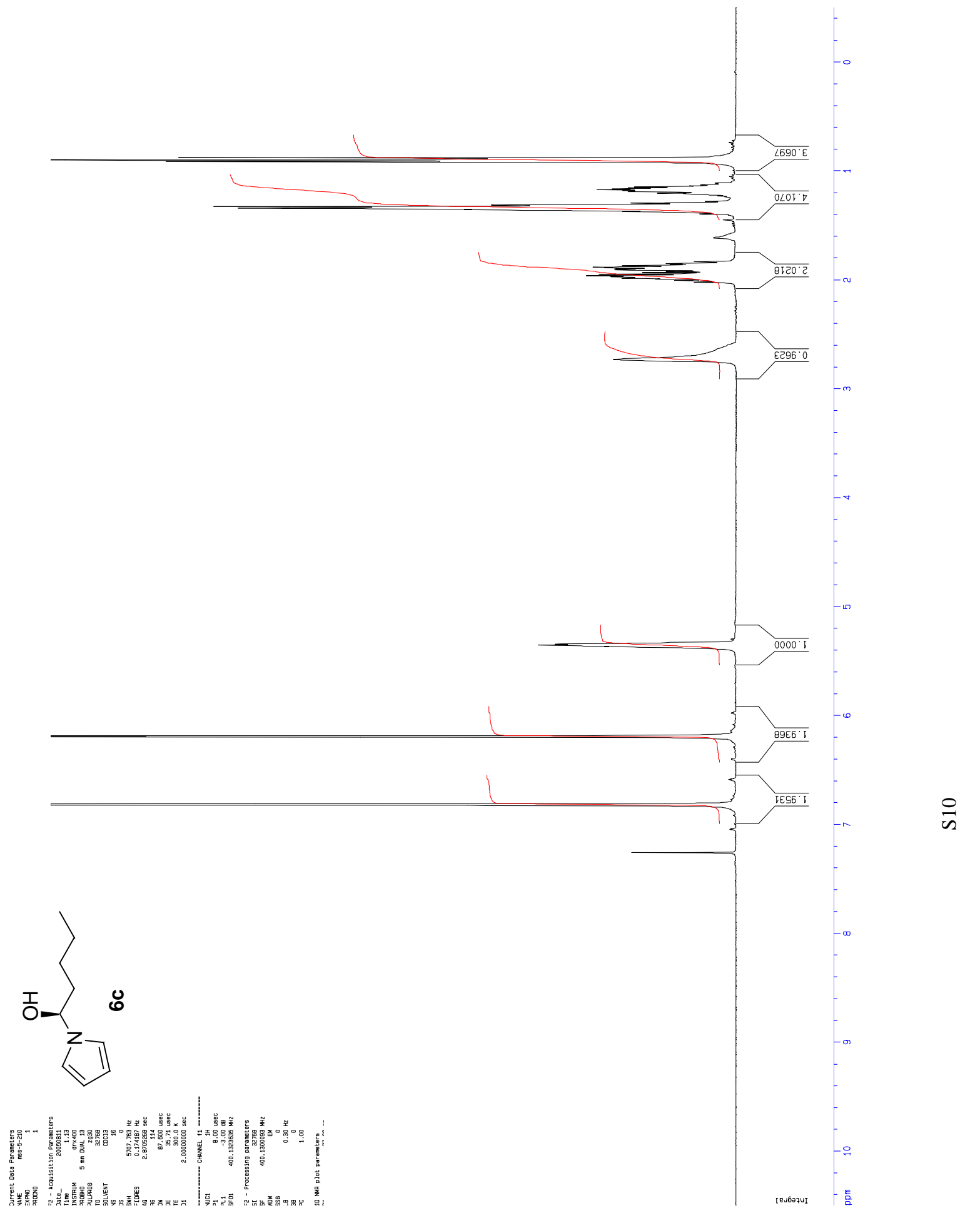



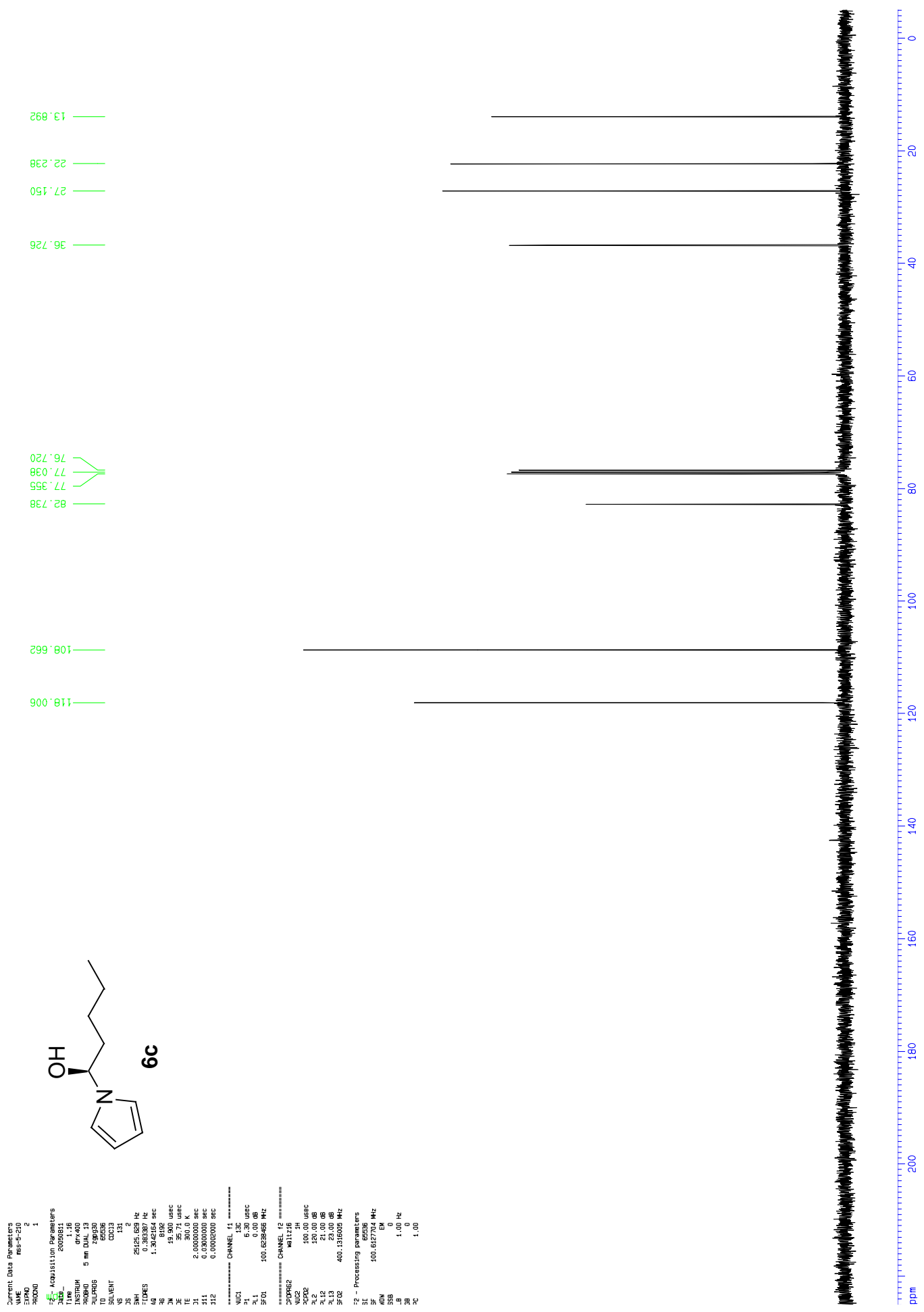

$\bar{v}$ 


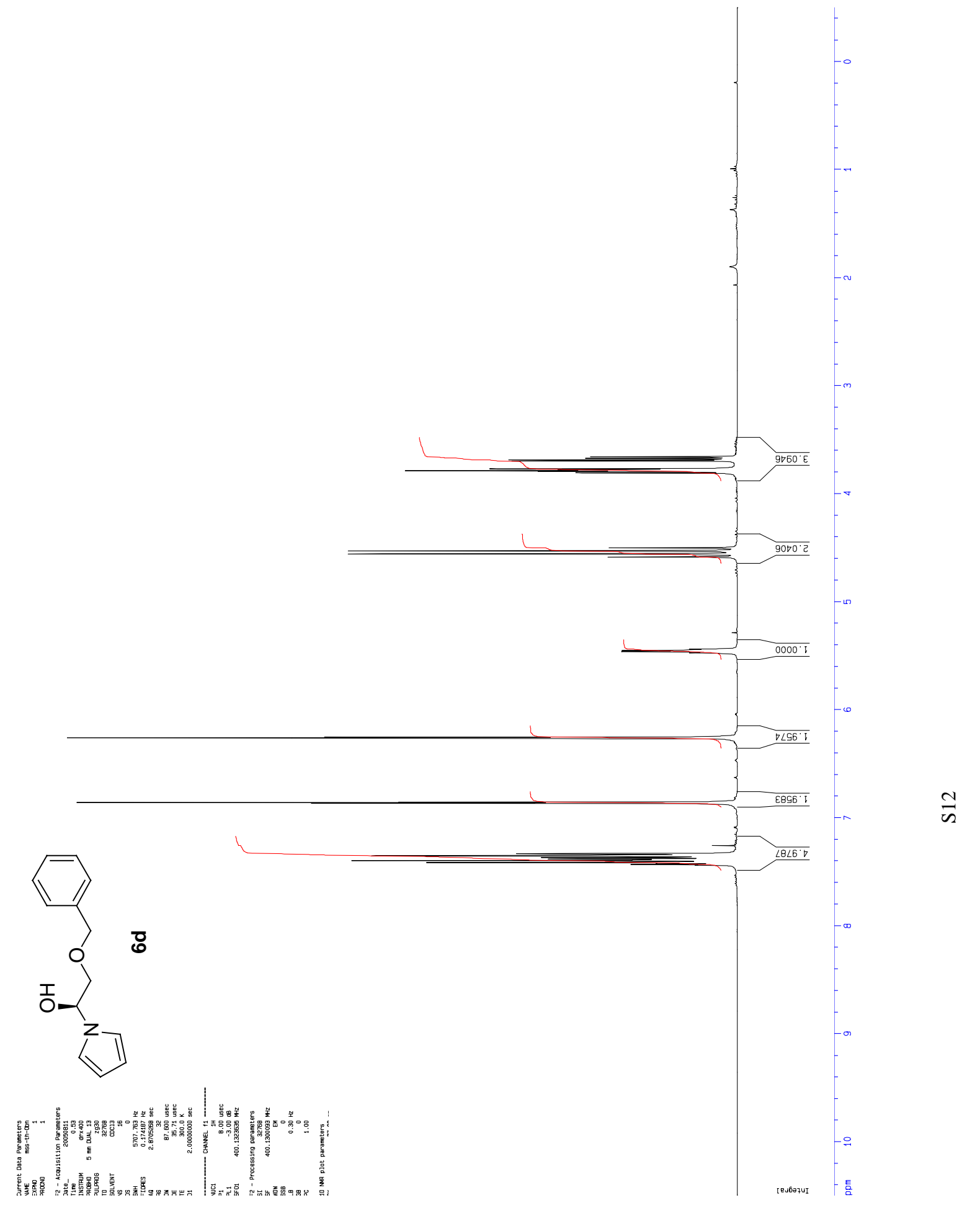




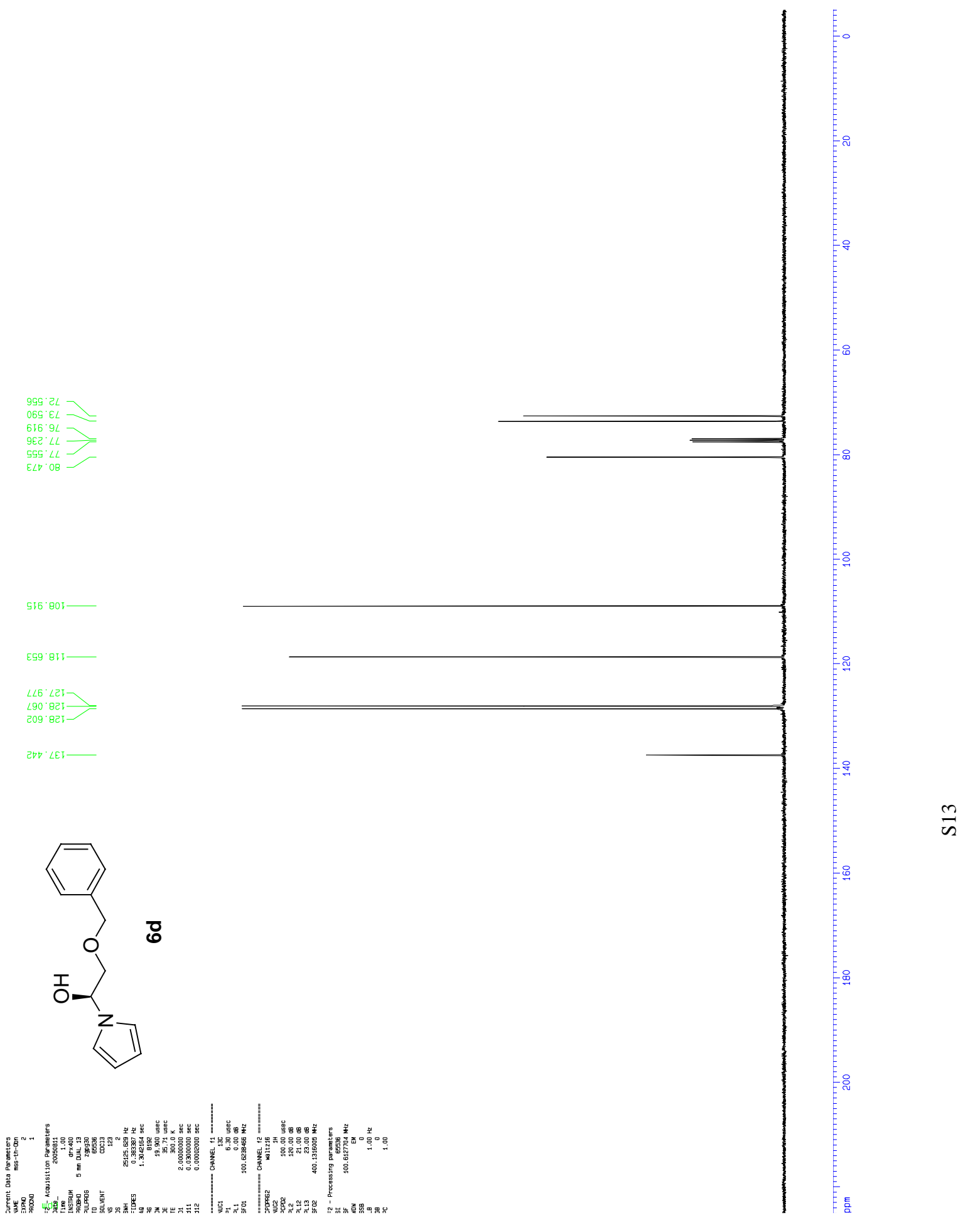




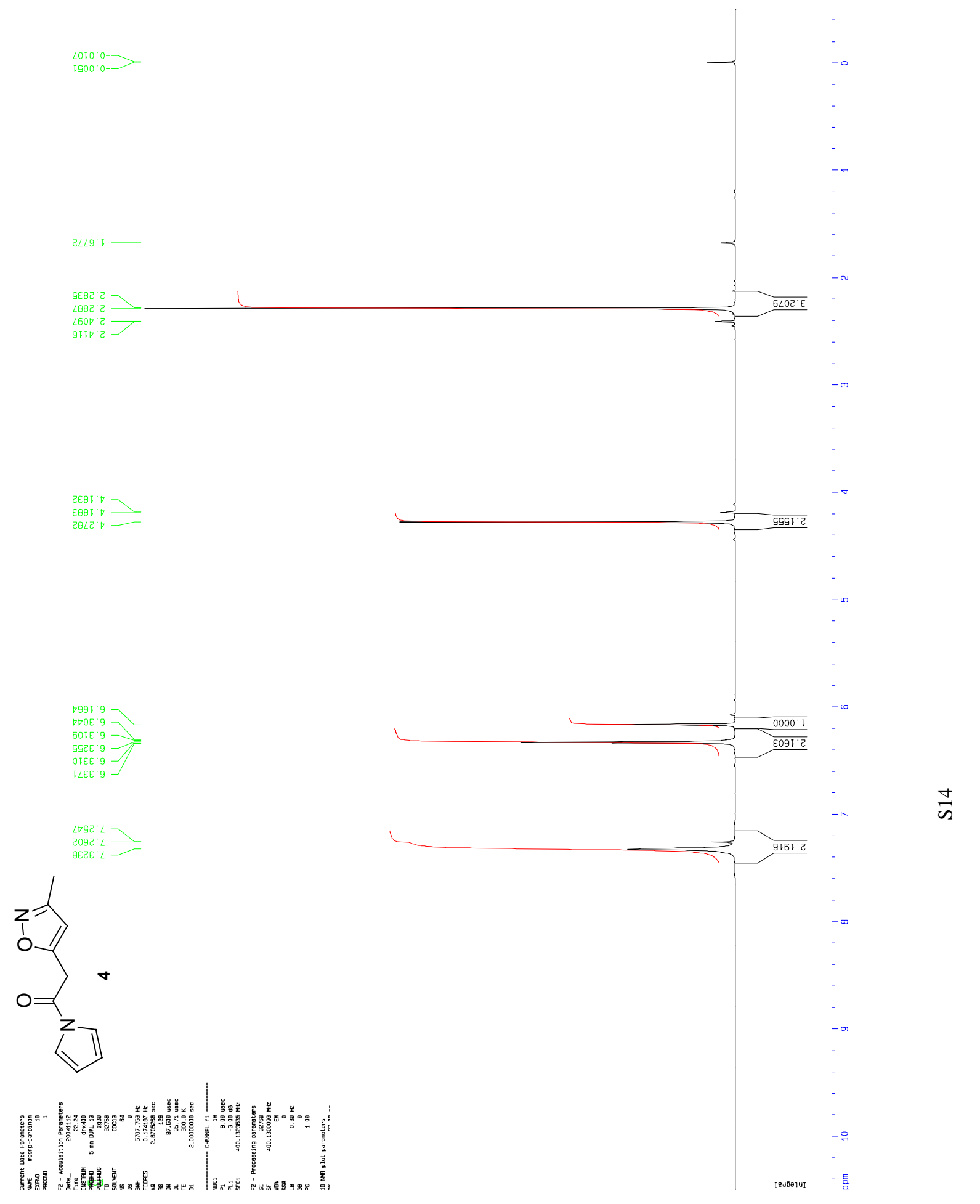




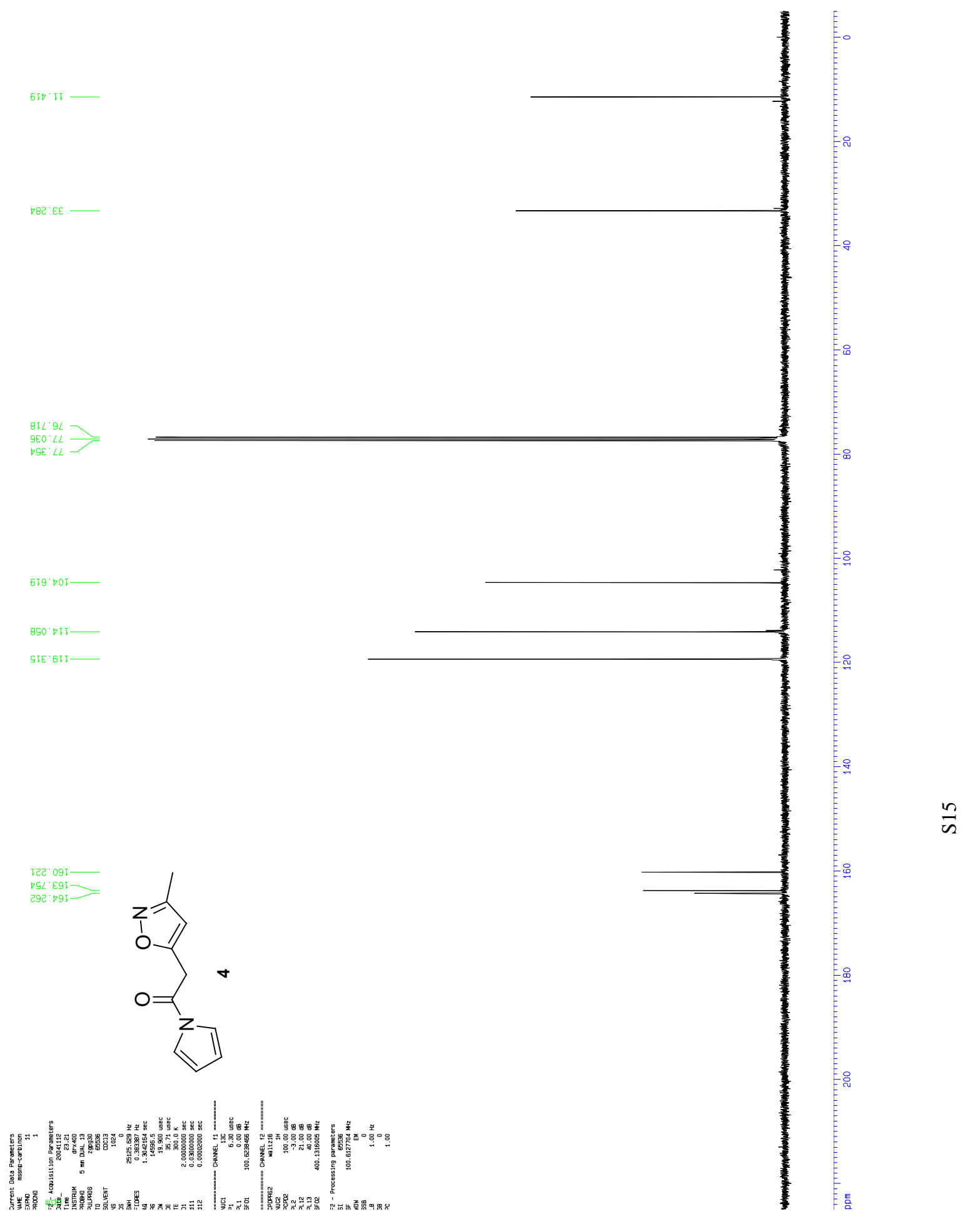




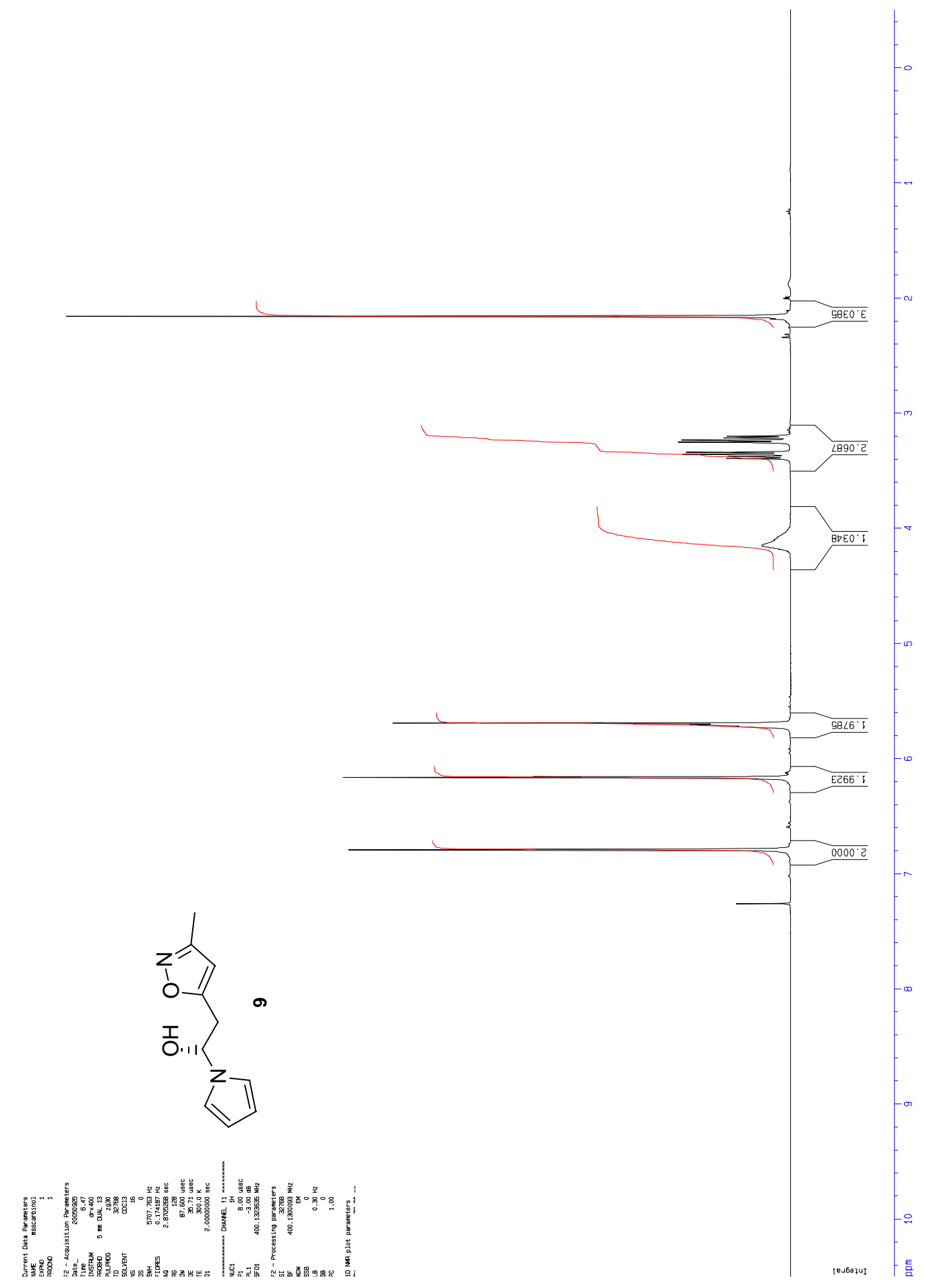




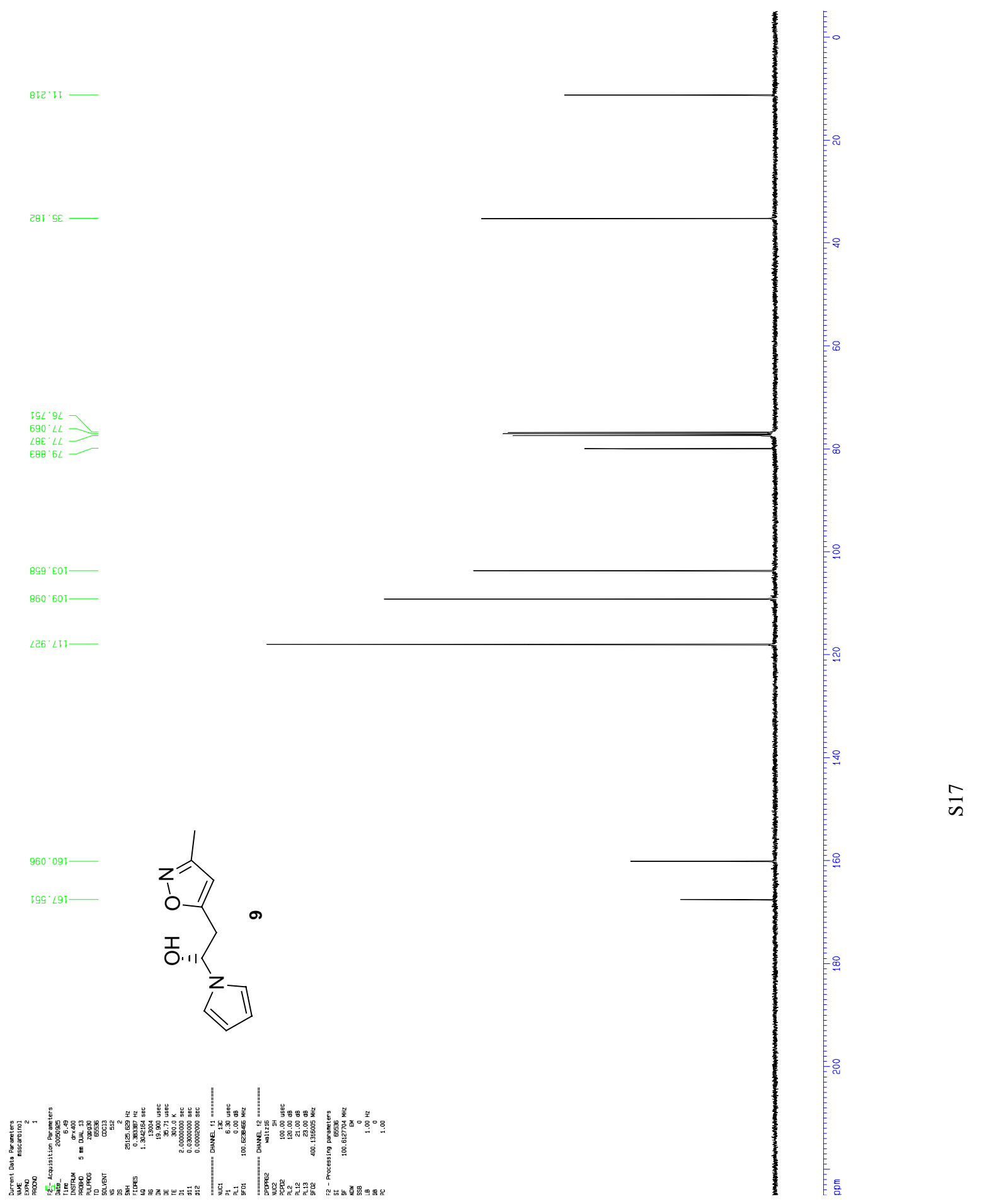




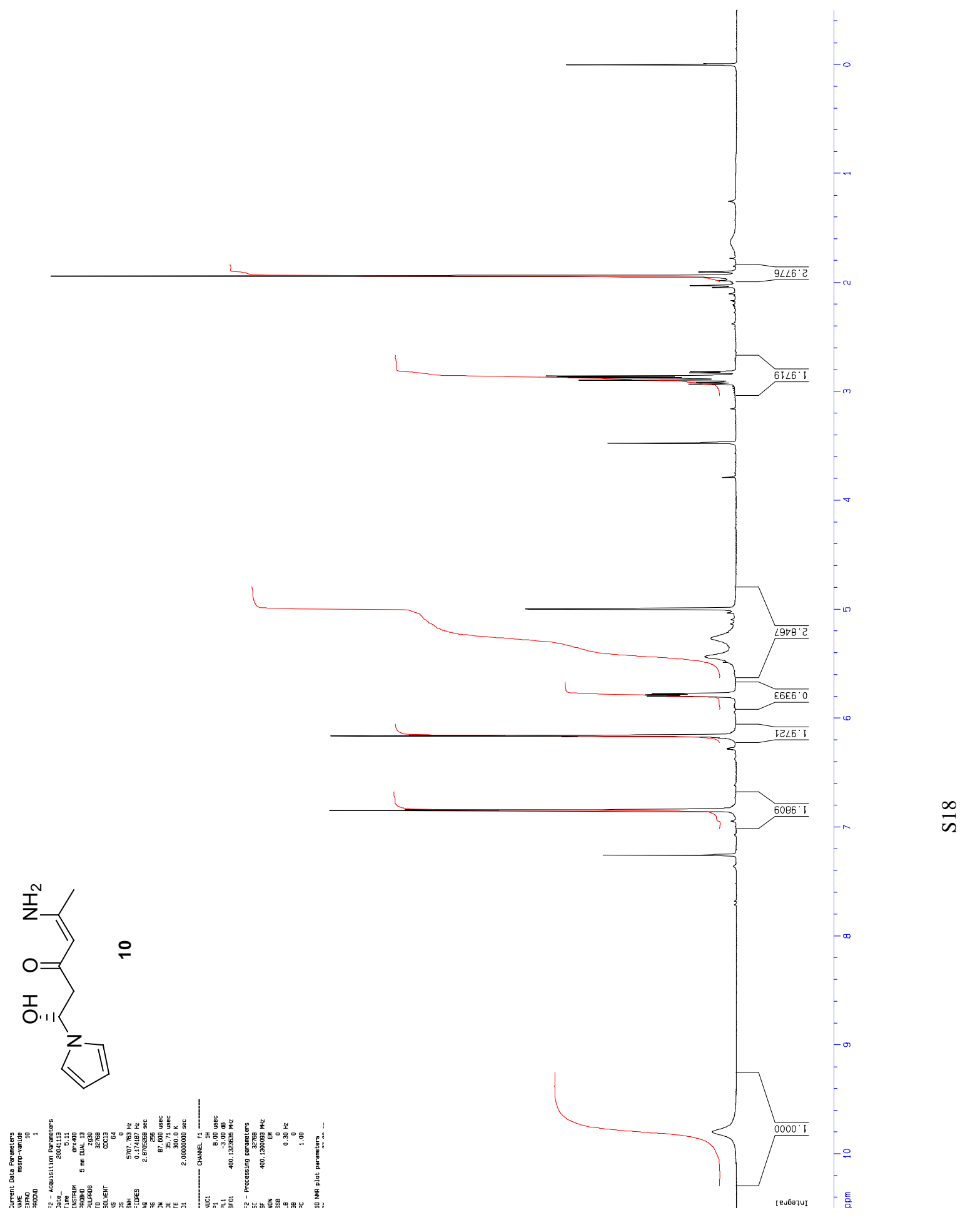




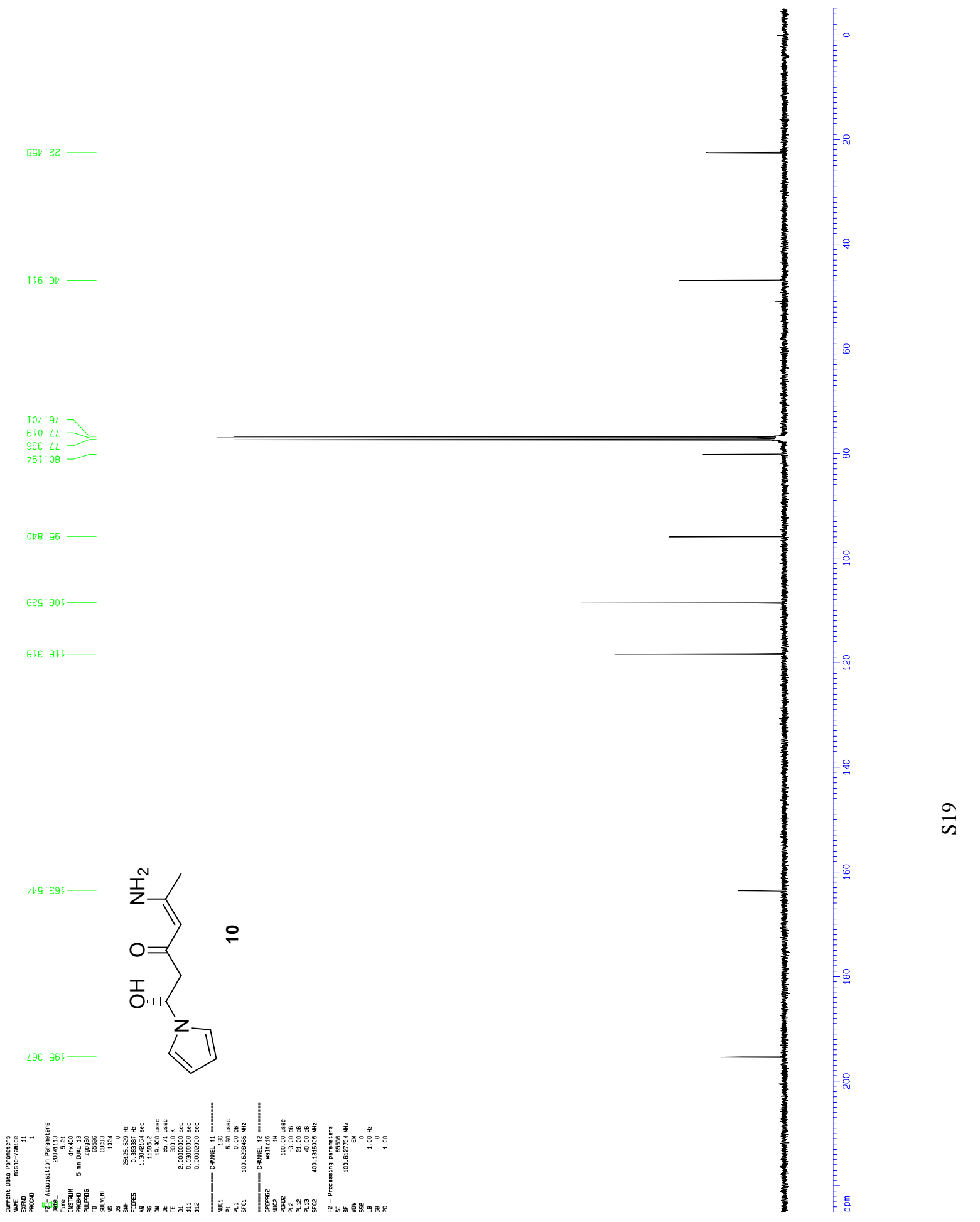




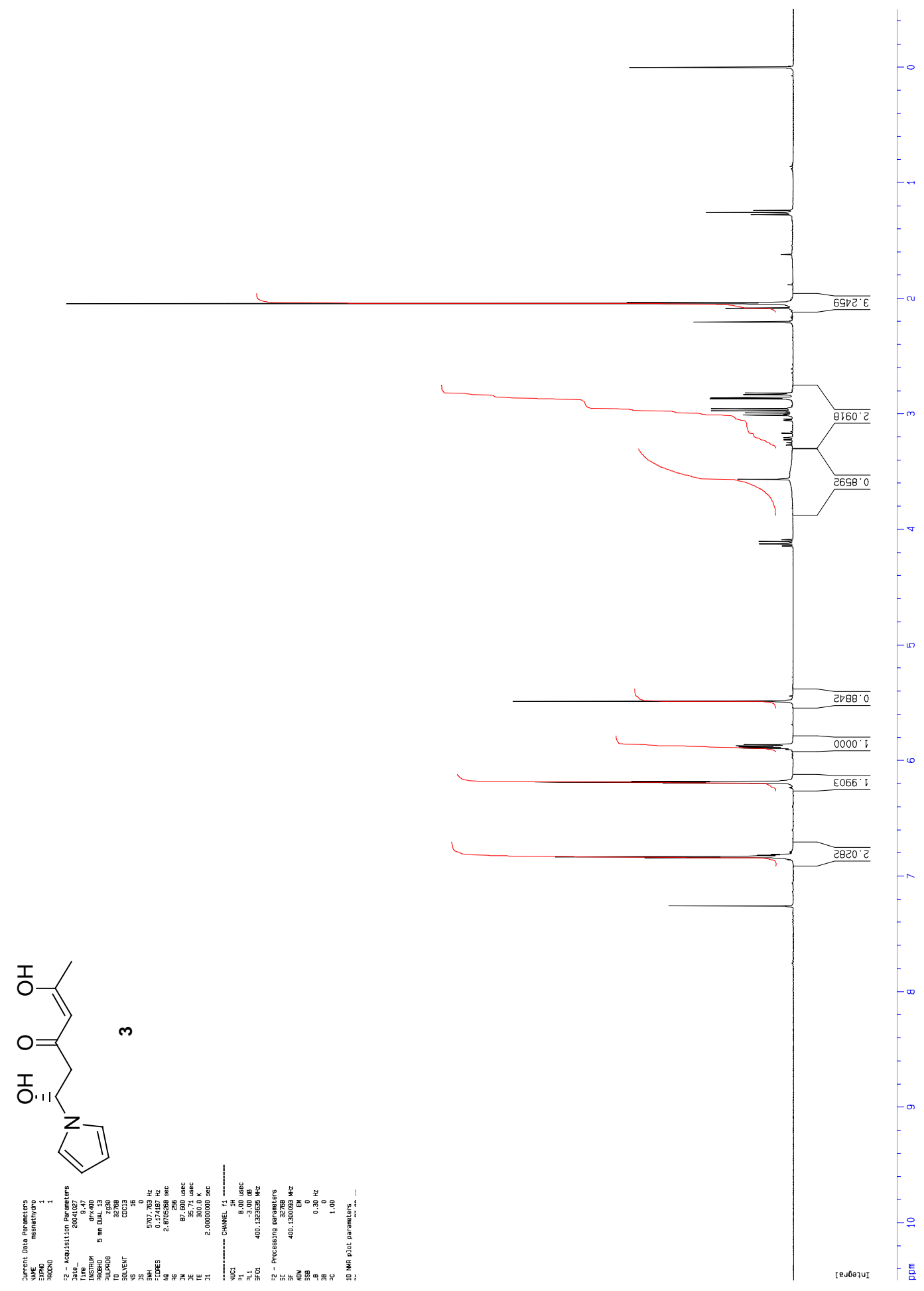




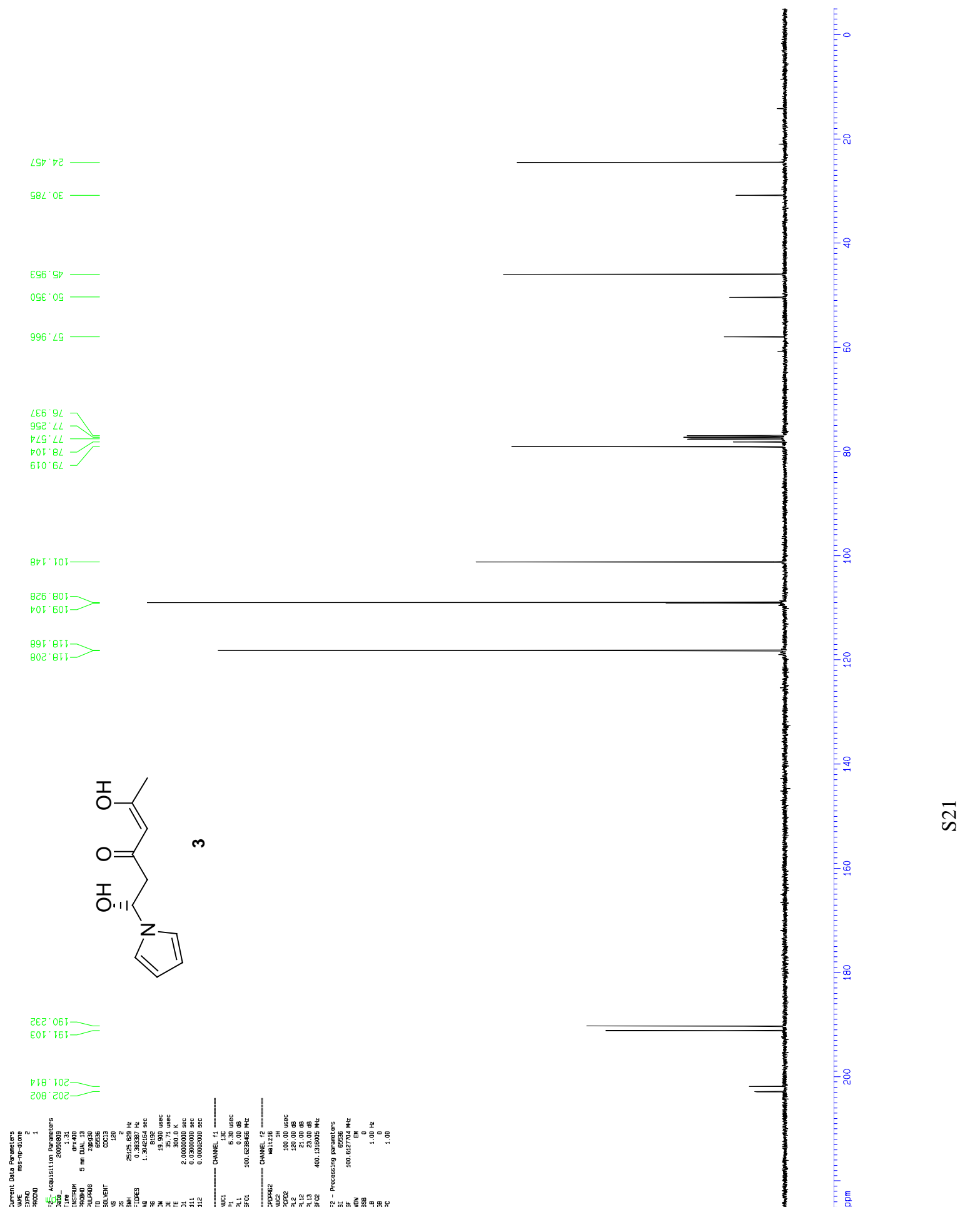



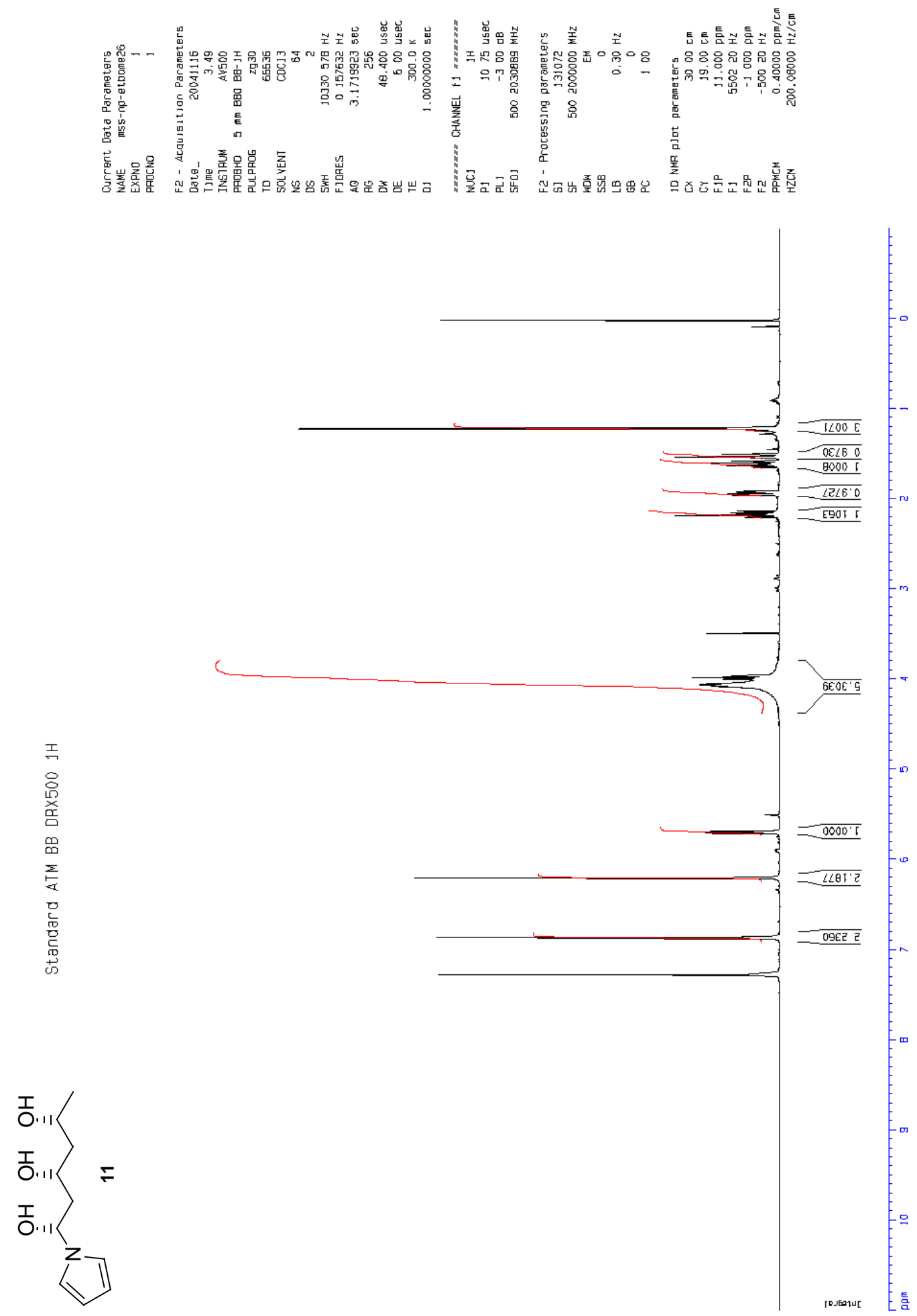

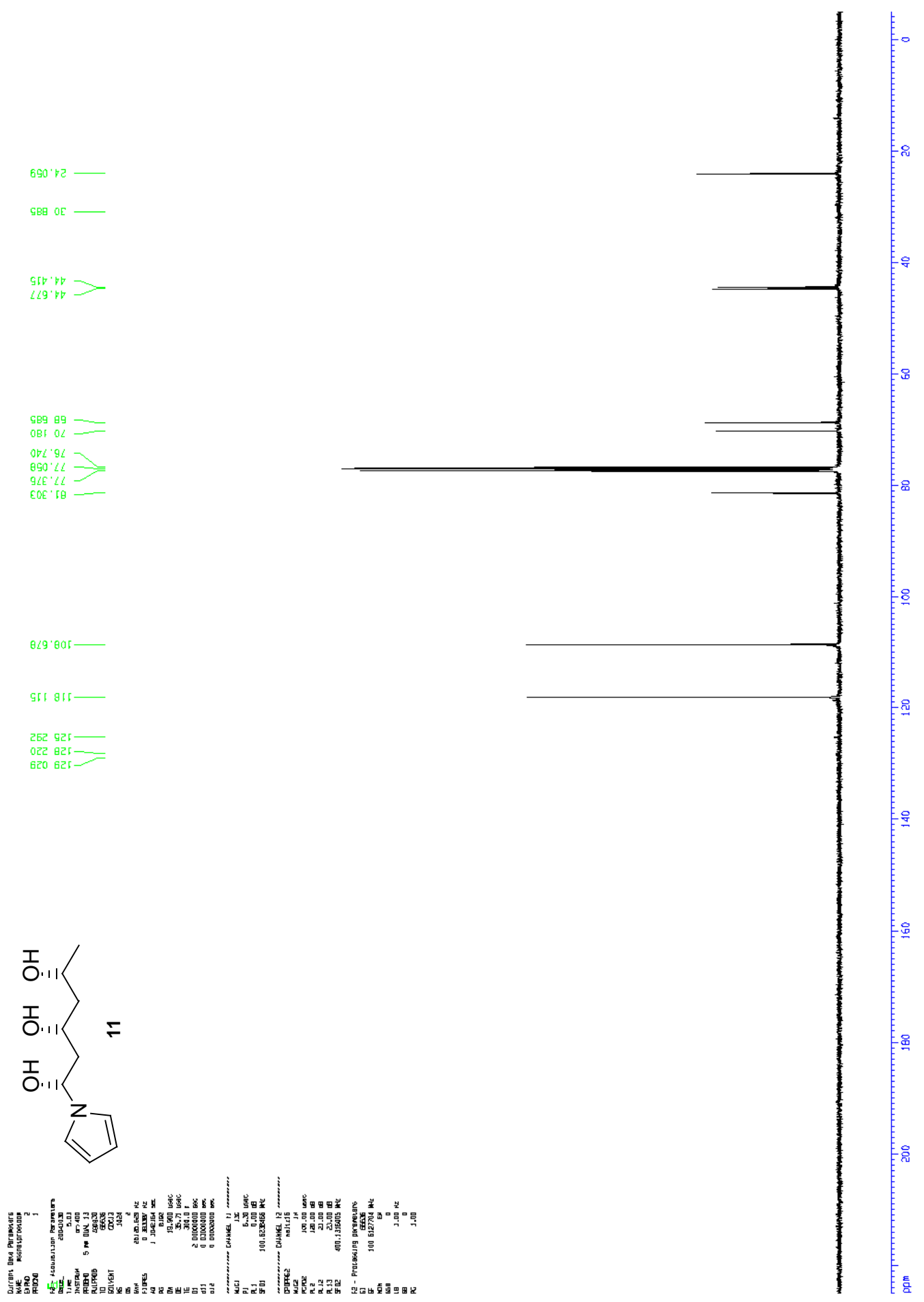


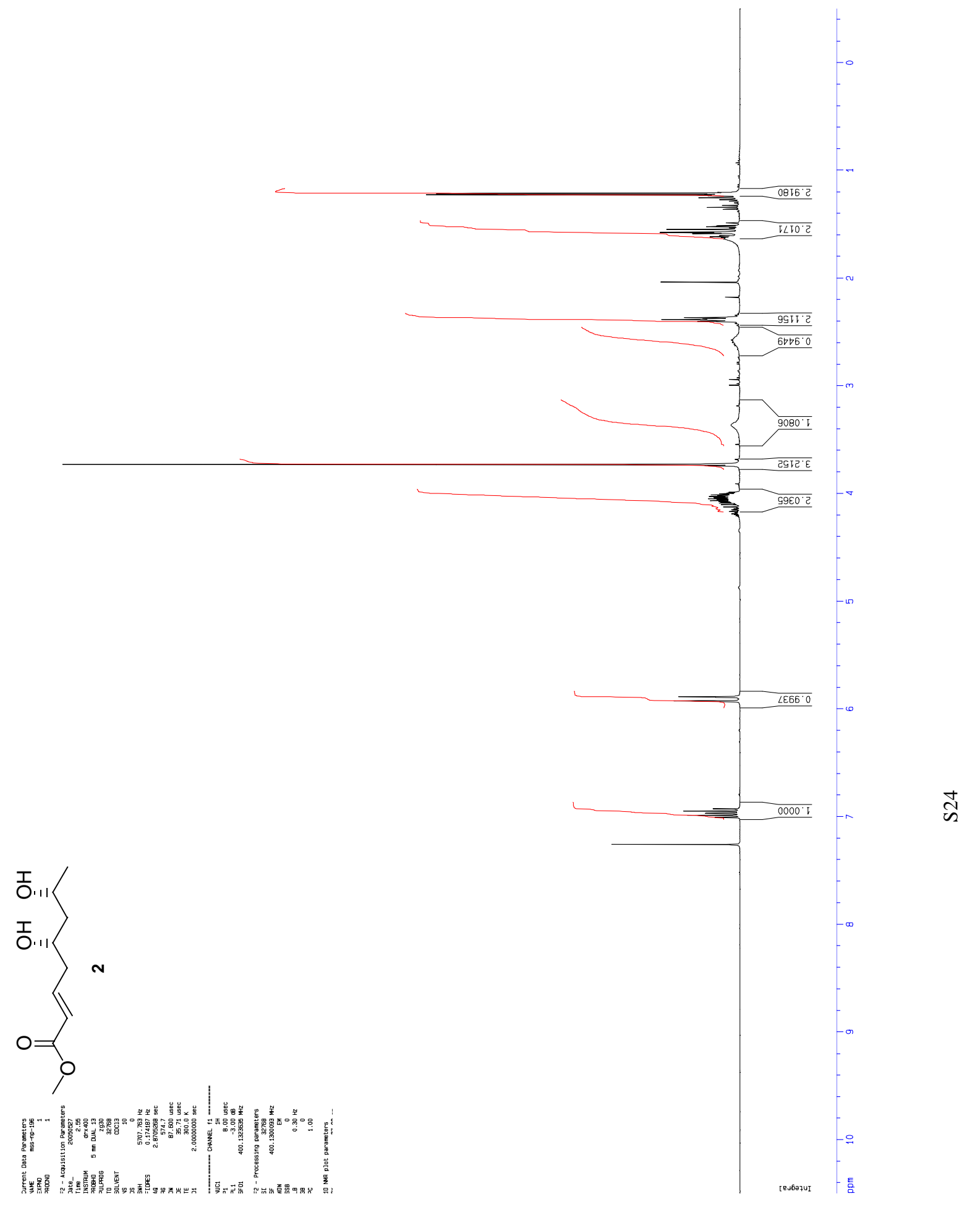




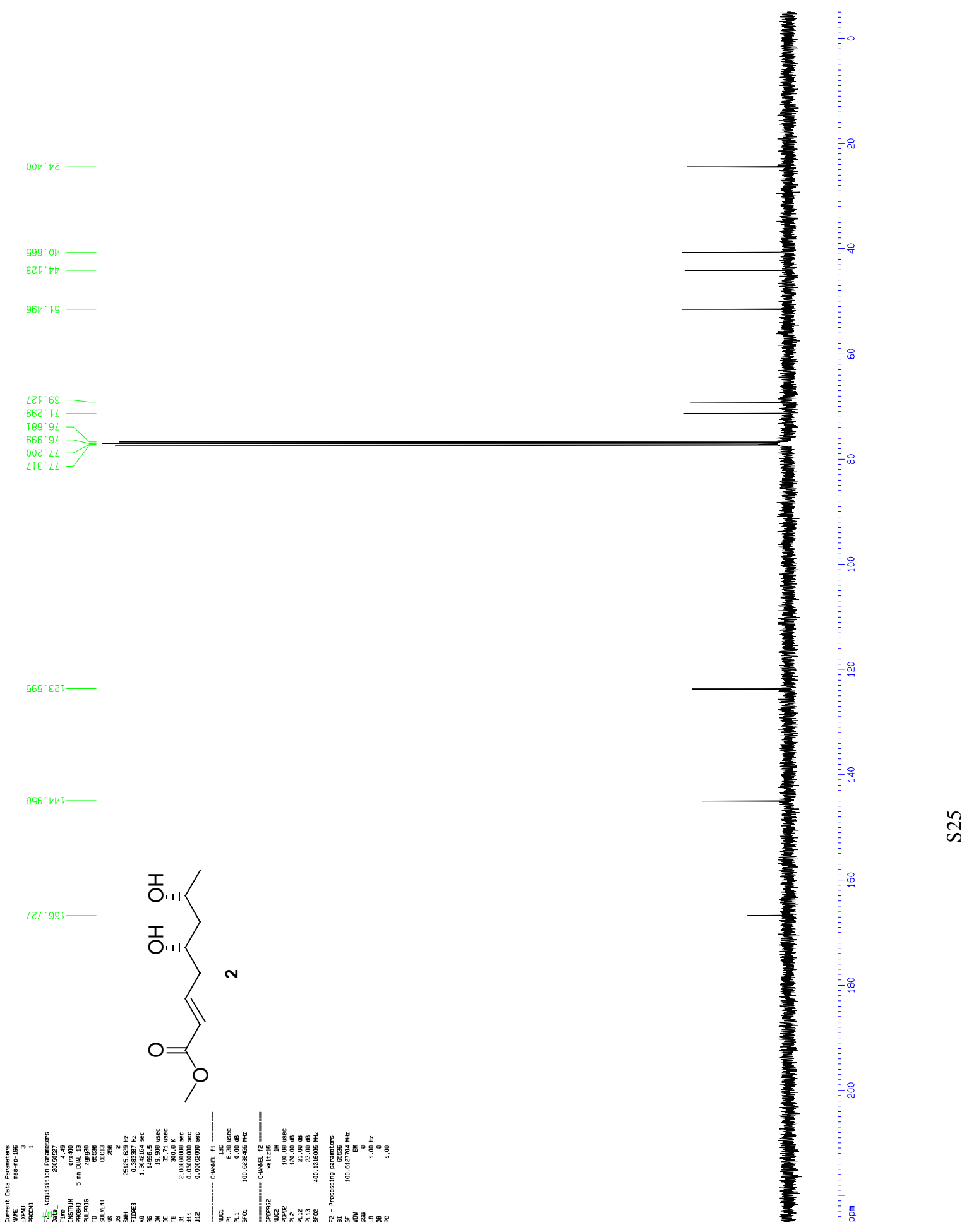




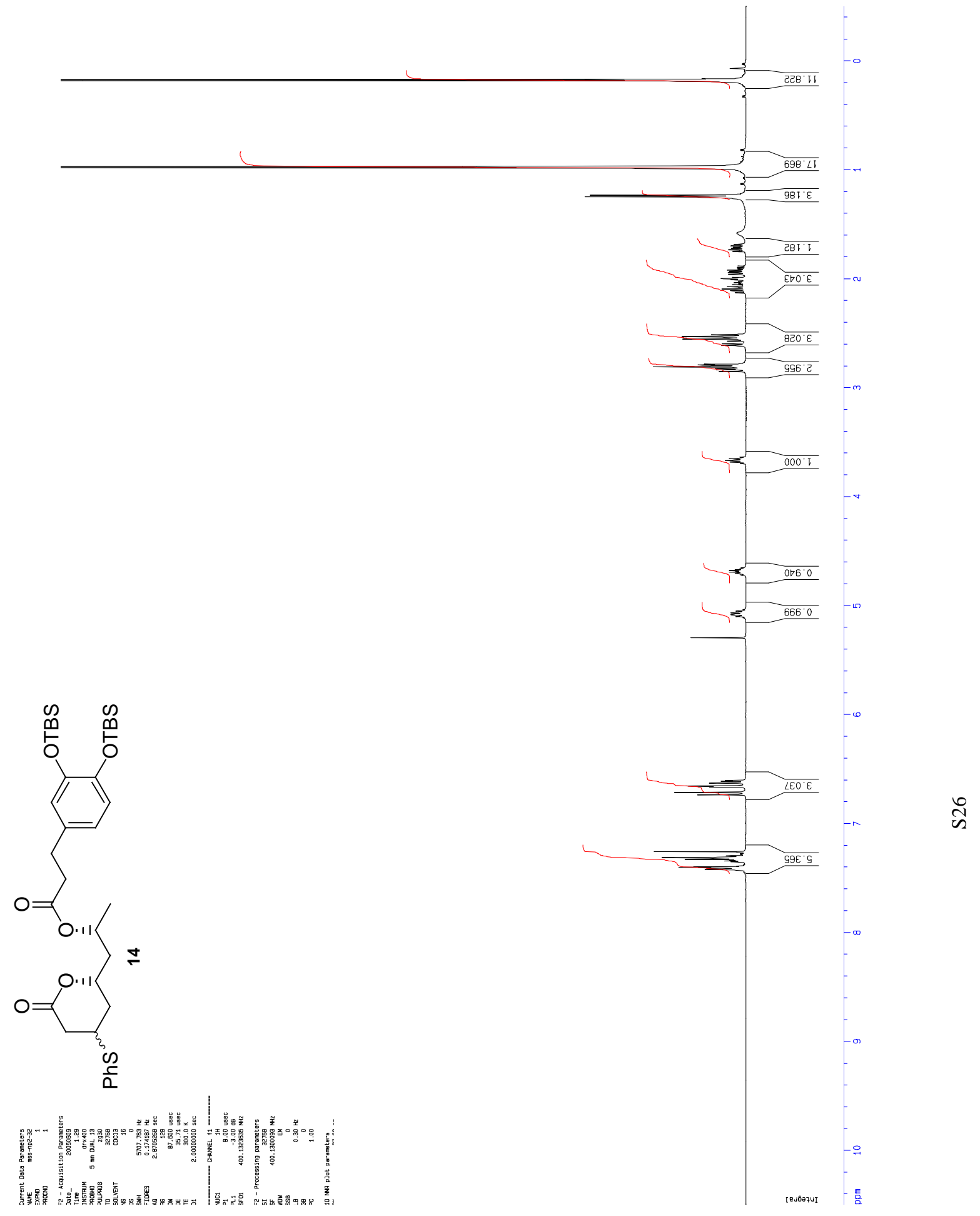




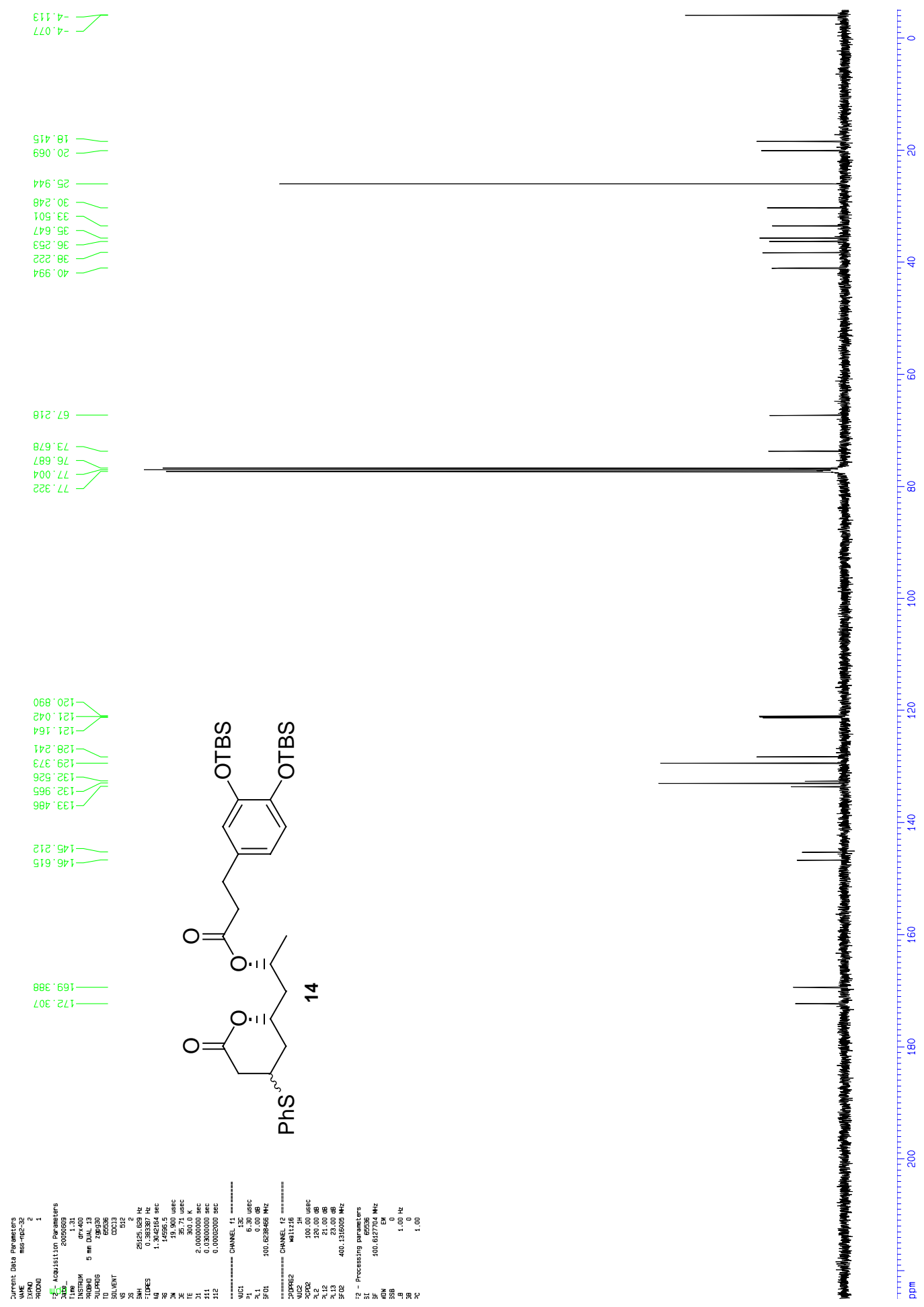

송 


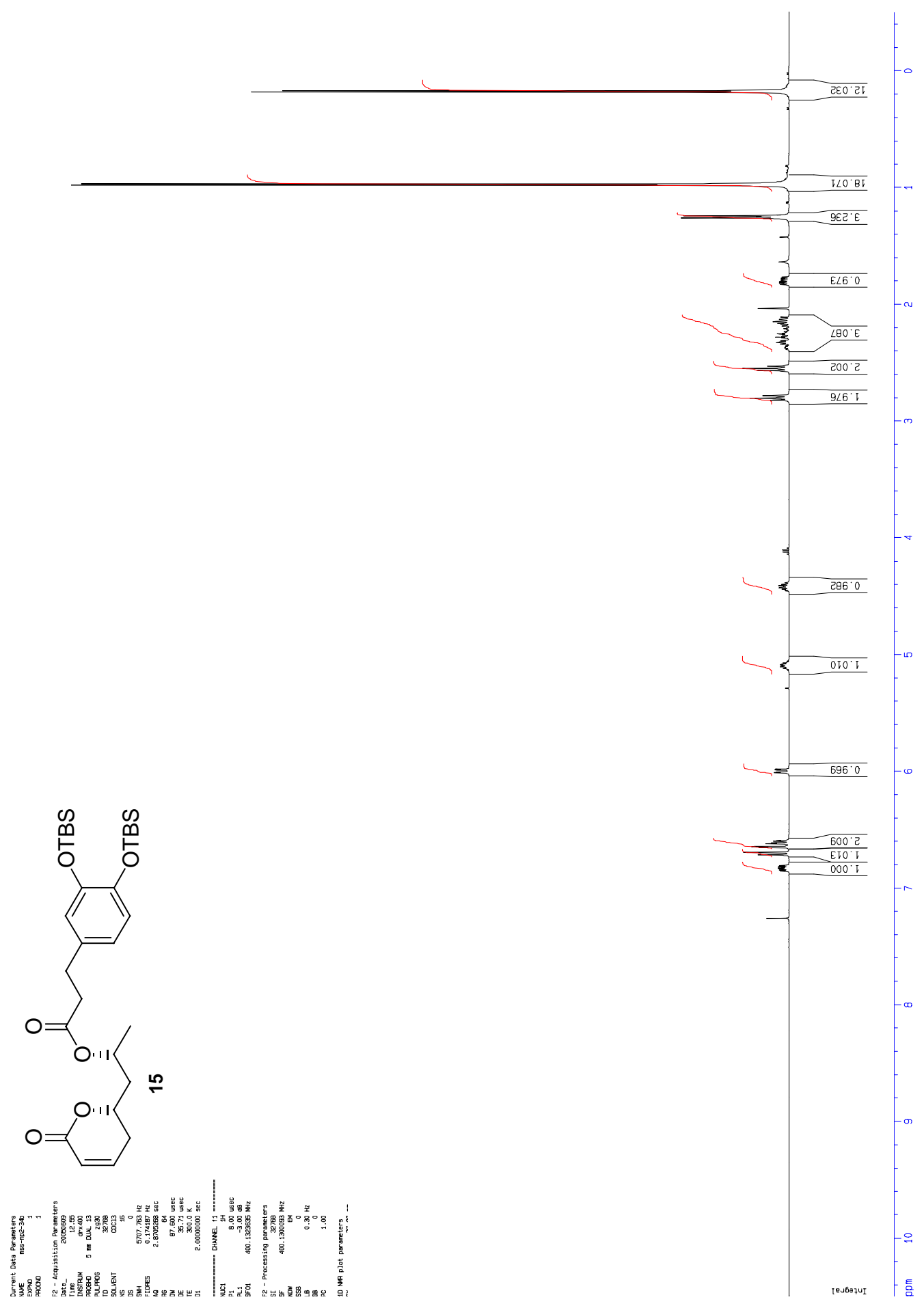




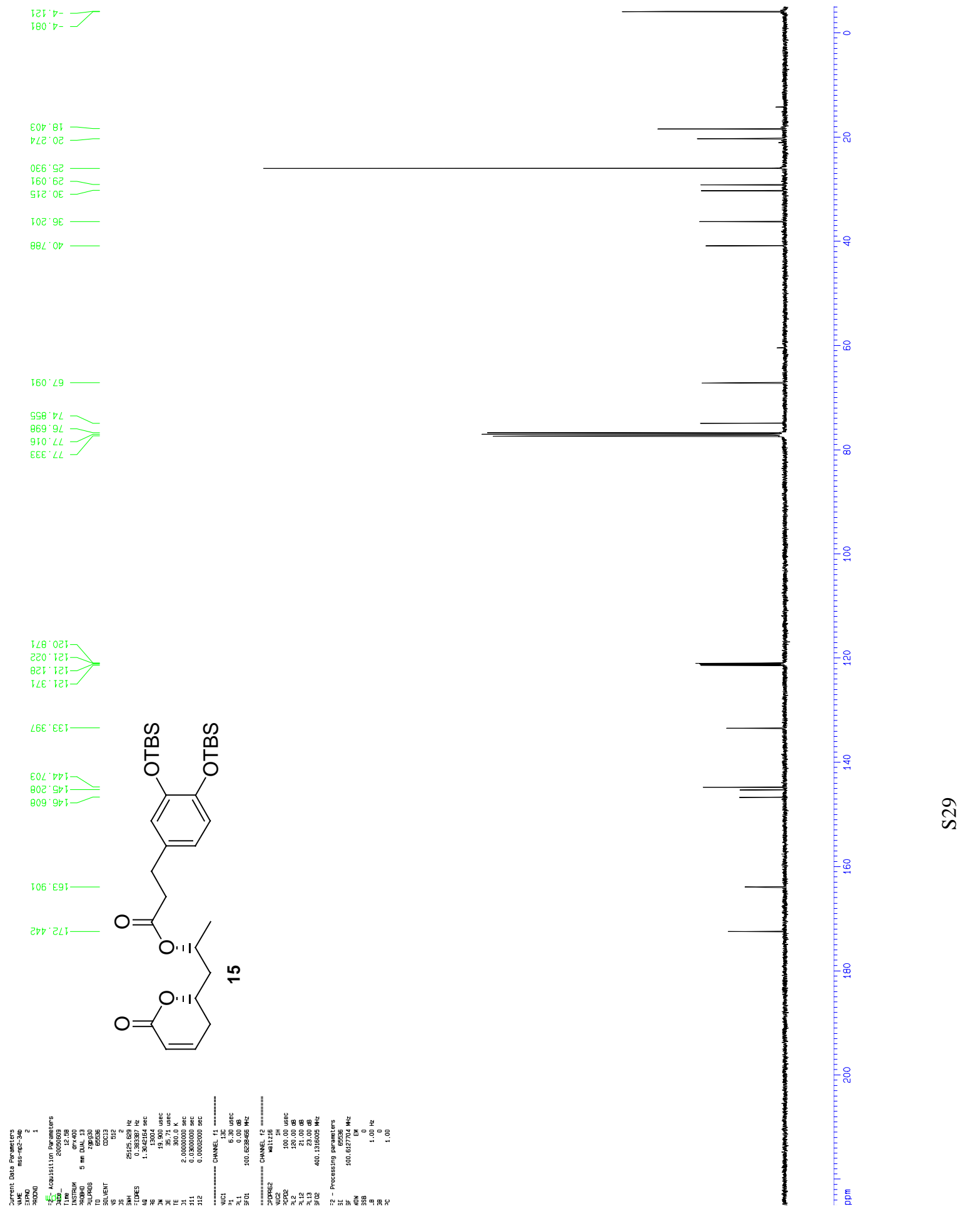




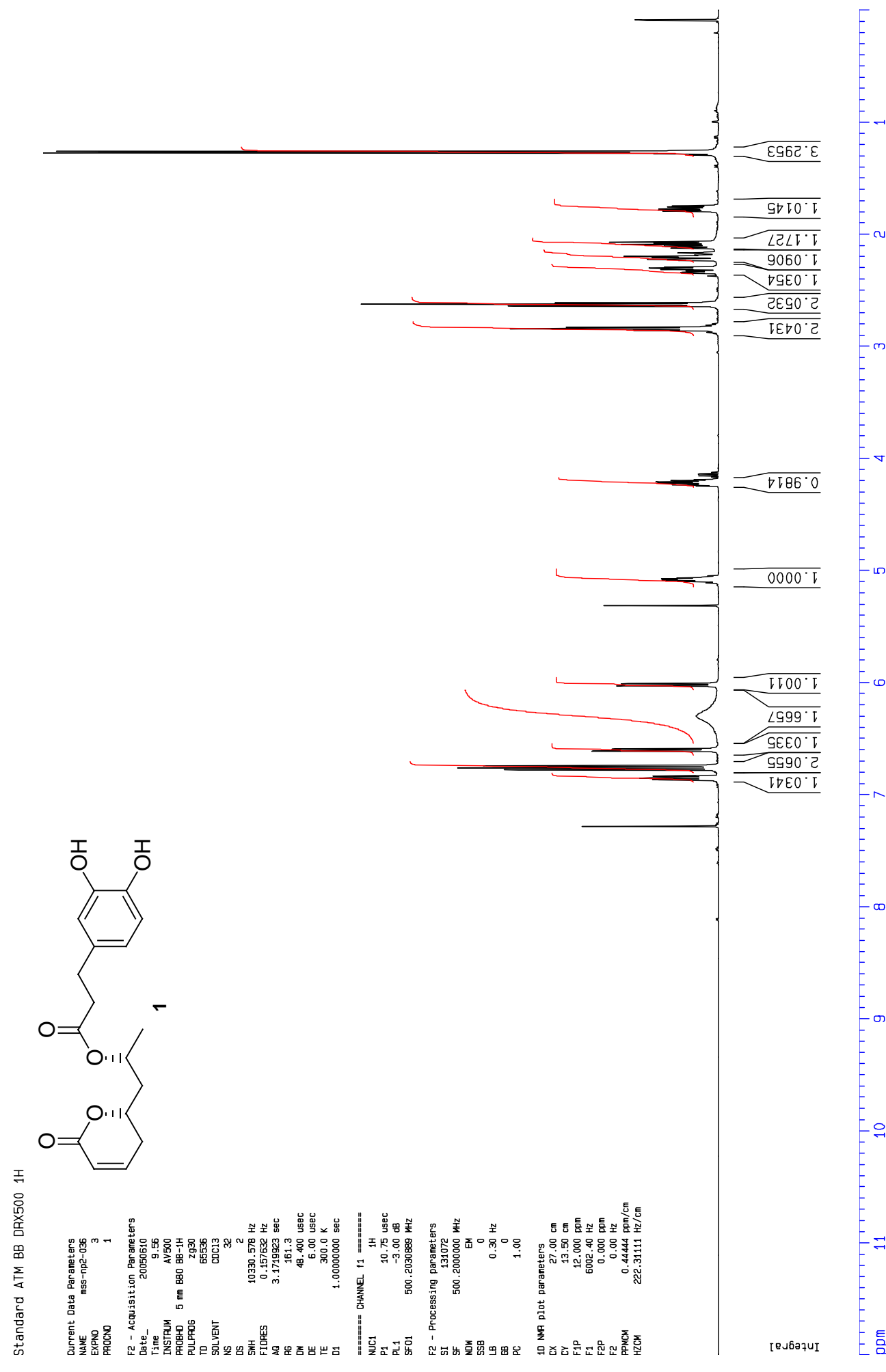



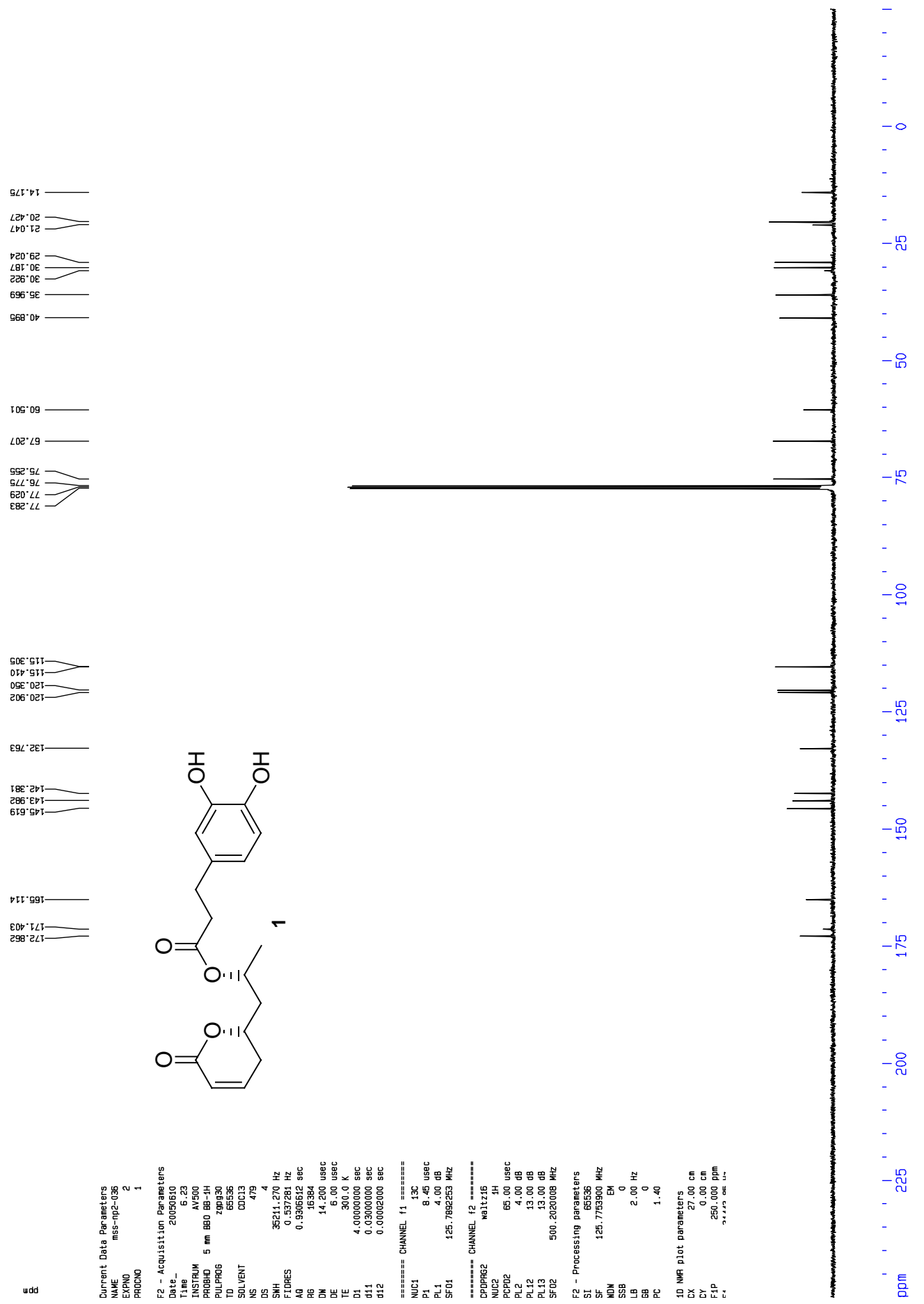